\title{
A PRODUÇÃO E O DESIGN INDUSTRIAL DE ARTEFATOS PARA CRIANÇAS NA HISTÓRIA - Uma revisão
}

\author{
Valéria Ramos Friso \\ Mestranda PPGDesign - UNESP, Bauru \\ valeriafriso@yahoo.com.br \\ João Carlos Riccó Plácido da Silva \\ Doutorando PPGDesign - UNESP, Bauru \\ Joaocarlos_placido@hotmail.com \\ Paula da Cruz Landim \\ Livre-Docente PPGDesign-UNESP, Bauru \\ paula@faac.unesp.br
}

\begin{abstract}
Resumo: A produção industrial sempre convergiu para diferentes fins, de acordo com as mudanças econômicas culturais e sociais da sociedade, em função das épocas. Os objetos produzidos exclusivamente para crianças não foram produzidos seguindo os mesmos pretextos que os destinados aos adultos. Isso se deve ao fato $d$ a sociedade ter negado o status de categoria da infância durante muitos séculos. A partir das mudanças de paradigmas sobre o papel das crianças na sociedade começaram a surgir diferentes interesses na produção com vistas a atender tal público. Os objetivos implícitos nesses objetos revelam as expectativas que seus criadores tinham sobre as novas gerações, trazendo à superfície as ansiedades e desejos dos adultos sobre aqueles que no futuro ocupariam seus lugares. Acontecimentos históricos, movimentos artísticos e teorias sobre desenvolvimento são facilmente detectados na produção para as crianças durante todo o século XX.
\end{abstract}

Palavras-chave: design, infância, crianças, história, produção, indústria.

\section{INTRODUÇÃO}

A posição das crianças na sociedade muda de acordo com o tempo e com o ambiente em que estão inseridas. Da mesma forma, os produtos voltados para esse público possuem diferentes perfis e enfoques, dependendo da visão que os adultos, que são os principais responsáveis por oferecê-los, têm da infância. A criança esteve durante toda a história na dependência da concepção adulta sobre seus papeis e suas necessidades. Quando a criança passou a ser entendida como ser em formação, porém pensante e atuante, passaram a existir produtos específicos para o público infantil embutidos de interesses políticos e sociais. Também é possível encontrar tentativas de 
respostas a suas necessidades específicas, mas buscando ainda interpretá-las sob a perspectiva do adulto. O presente artigo busca correlacionar os objetos utilizados pelas crianças ao contexto histórico e social em que se encontravam e como a visão do adulto sobre a infância interferiu na produção para esse público. Pretendemos apresentar casos de produtos que claramente sofreram influencias socioculturais através dos tempos.

\section{A PRODUÇÃO PARA CRIANCAS}

A produção e consumo de objetos sempre esteve atrelado a princípios sociais de sua época. Existiram diferentes produtos destinados à nobreza e ao clero, a homens e mulheres, e não foi diferente com as crianças. A forma como entendemos seu papel se manifesta através de nosso comportamento com relação as mesmas. Os objetos oferecidos para esse público sempre estiveram em consonância ao contexto histórico e a concepção de infância que existia ali. A produção para a criança veio muito tardiamente, e atendia mais às expectativas dos adultos que suas próprias. A criança pode ser entendida como reflexo dessas expectativas depositadas sobre si. (MERLEAUPONTY, 1990)

Durante séculos a infância foi entendida como uma condição desprivilegiada, não como uma categoria. As crianças eram desconsideradas enquanto seres munidos de características próprias, eram entendidos apenas como "adultos pequenos", como se apresentassem um tipo de deficiência. Durante a Antiguidade até a Idade Média a mortalidade infantil era muito alta e o futuro das crianças era determinado pelos interesses de seu pai. Não existia sentimento de amor pelas crianças, que podiam ser mortas vendidas ou simplesmente abandonadas à própria sorte. Por volta de 7 anos passavam a disputar o mesmo espaço dos adultos, nas funções e na vida social. (ARIES, 1978)

No fim do século XVI começa a surgir uma necessidade de diferenciar as crianças por meio de suas vestimentas. No século XVII as crianças da nobreza já não aparecem mais vestidas como adultos, e essas passaram retratadas em inúmeras situações sozinhas, ou como centro da composição. O traje adotado na maior parte da Europa fora a túnica, abandonada pelos adultos desde o século XIII. A túnica era utilizada tanto por meninos quanto por meninas. O diário da infância de Luís XIII mostra quão importante passou a ser o traje da criança que tornavam visíveis as etapas do crescimento do homem. Esse foi um passo muito relevante para a mudança no sentimento da sociedade a respeito das crianças. (ARIES, 1978)

Durante o século XVII pensadores já apontavam para uma infância mais independente, com características e necessidades próprias. Rousseau enaltecia a capacidade de pensar, sentir e raciocinar das crianças, bem como sua pureza e sensibilidade. No século XVIII o Romantismo mudava de forma sutil seus conceitos, atribuindo às crianças uma profunda sabedoria, sensibilidade estética mais apurada e maior entendimento de verdades morais. (ARIES, 1978)

As Figuras 01 e 02 apresentam como a criança era retratada na metade do século XVIII, estando em igualdade com os adultos na posição e vestimenta e como essa concepção mudou na imagem do século XIX, com as crianças vestidas de forma diferenciadas demonstrando as etapas de desenvolvimento. 


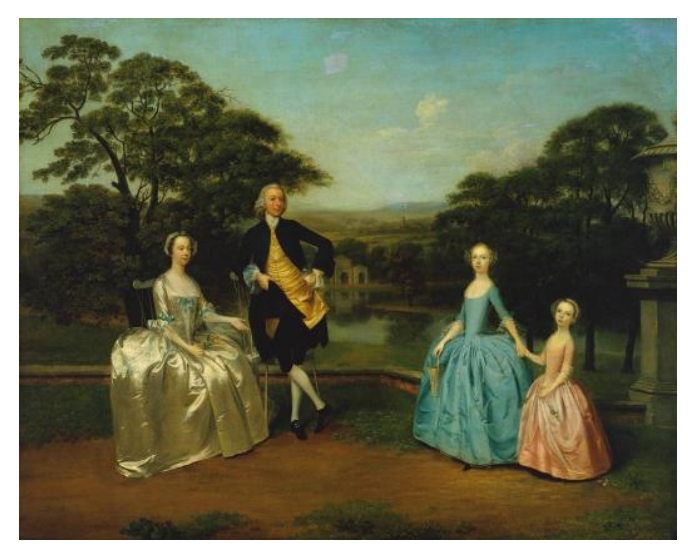

Figura 1 - Retrato The James Family (metade século XVIII) - Arthur Devis - As crianças são retratadas com o mesmo destaque que os adultos

(Fonte: https://www.tate.org.uk, 2007)

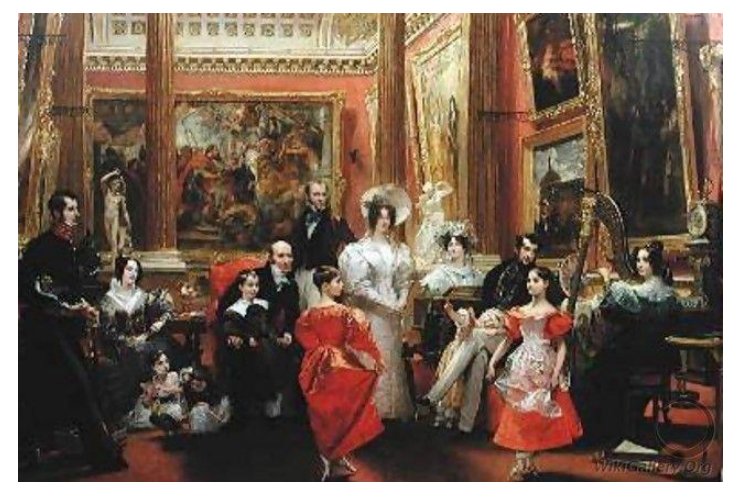

Figura 2 - Retrato família Grosvenor (1831) - C.R. Leslie - Os jovens estão representados distintivamente dos adultos

(Fonte: www.1st-art-gallery.com, 2013)

As vestimentas que distinguiriam os adultos das crianças surgiram primeiramente para os garotos, que já frequentavam escolas desde o final do século $\mathrm{XVI}$. As meninas por outro lado ficavam em casa e dividiam o cotidiano com as adultas, o que dispensava a necessidade de distinção. (ARIES, 1978) Rousseau defendia em suas publicações o uso por crianças de roupas largas, sem tentar definir as formas. (GONTIJO, 1987)

No final do século XIX as ideias de pensadores como Rousseau já se faziam presentes no cotidiano, e os objetos infantis eram produzidos em cores pastel e com representações de animais ou cenas que representavam canções infantis, que representavam a visão adulta sobre a infância em sua essência pura. Louças destinadas a adultos eram por muitas vezes decorados com aves e mamíferos, associando-se com a caça, mas as louças infantis passaram a ser decoradas com animais antropomorfizados, buscando uma empatia maior por parte das crianças, figura 03. As observações sobre a falta de infantilidade feitas em visitas às escolas da Grã-Bretanha, devido a lei da educação de 1870 e o nascimento da preocupação dos jogos como uma 
atividade crucial para o desenvolvimento infantil levaram ao uso de figuras de animais em seus artigos. (FORTY, 2007)
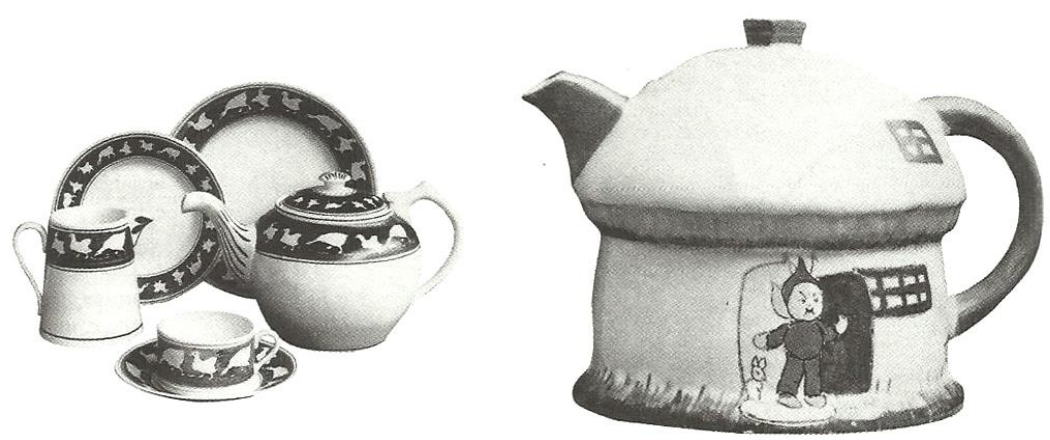

Figura 3 - Louça infantil Heal’s 1925; Bule de chá, ceramica Shelley1926, Mabel Lucie Attwell

(Fonte: FORTY, 2007)

Apesar do sentimento com relação à infância já se distanciar muito daquele da idade média durante todo o século XIX, apenas no final do século a infância só foi reconhecida como categoria. Kate Wiggin em "Children's Rights" em 1892 já buscava difundir os direitos das crianças, mas apenas em 1948 a Organização das Nações Unidas aprovou a Declaração Universal dos Direitos Humanos, onde estes direitos foram reconhecidos de maneira detalhada e implícita.

Em 1959, iniciou-se a preparação de uma nova declaração de direitos específicos para as crianças, assinado em 1989 na Convenção sobre os Direitos das Crianças na ONU.

Walter Benjamin (2004) faz críticas as adaptações dos contos infantis ocorridas na primeira metade do século XX, a fim de se adequarem ao ideal de criança que havia se instituído. Cita como exemplo, as mais de 17 edições dos contos dos Irmãos Grimm, antes rodeados de casos de morte, traições e cenas trágicas, que acabaram por se resumir em contos suaves, ainda que com certa dramaticidade, mas muito mais otimistas bucólicos e desprovidos de malícias. O autor aponta a forma como personagens como o ogro até bem pouco tempo atrás um personagem provavelmente muito comum no cotidiano alemão, tornou-se estranho à sensibilidade moderna. (BENJAMIN, 2004)

\section{O IMPACTO DA HISTORIA NA PRODUÇÃO}

O século XX foi marcado por uma produção massiva para crianças, produtos esses que refletiam a introdução da categoria infantil na sociedade. Acontecimentos históricos e movimentos artísticos estiveram fortemente relacionados à produção para crianças, como forma de dar respostas as suas necessidades, porém mais do que isso, direcionar seu desenvolvimento. Surgiram muitos objetos que refletiam ideais políticos, como o colete desenvolvido por Laura Kriesch para sua filha em 1903 para permitir a liberdade de movimento evidenciando o socialismo radical de artistas Gödöllő em design moderno, figura 04. 


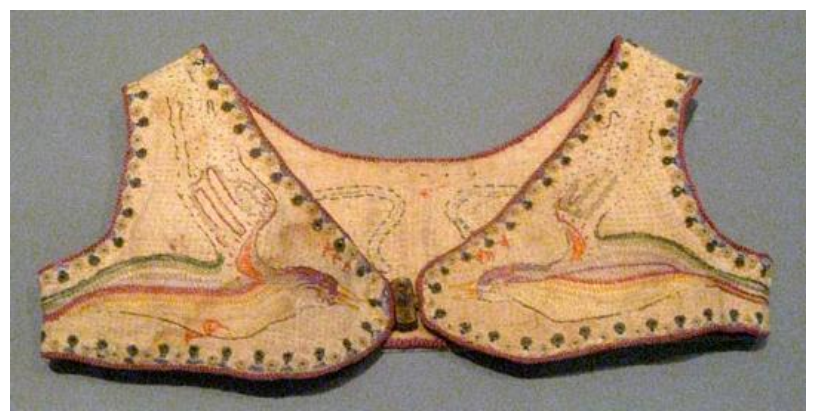

Figura 4 - Laura Kriesch. Colete bordado da criança. 1909 (Fonte: http://www.newyorksocialdiary.com/, 2012)

Temas como guerras foram amplamente utilizados na temática de jogos e produtos para a infância. As conquistas coloniais apareciam estampadas em aparelhos de jantar infantis como o Figli della Lupa (Filhos do Lobo), que era decorado com palmeiras, camelos, capacetes, rifles, tanques, e cabanas que em comemoração as conquistas italianas no Leste e Norte da África, figura 05.

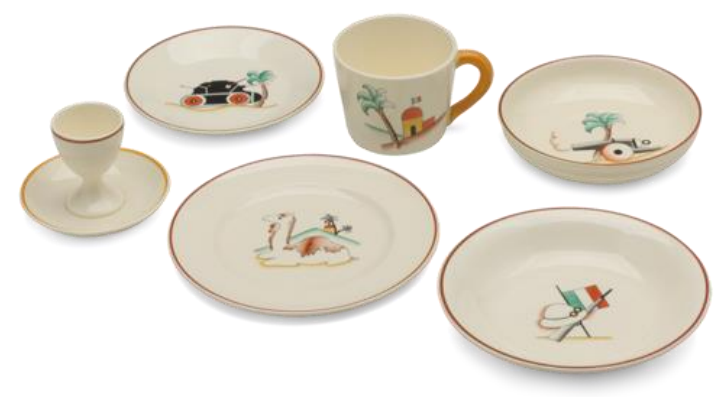

Figura 5 - Figli della Lupa (Filhos do Lobo) Conjunto de mesa. Richard Ginori 1930 (Fonte: http://centuryofthechild.tumblr.com/, 2012)

O Japão, nas primeiras décadas do século XX, quando se envolveu nos conflitos da Primeira e da Segunda Guerra Mundial, teve um grande salto tecnológico e industrial. A temática impressa nos produtos por vezes refletiam as tensões criadas pela velocidade da modernização do país e as aspirações militares dos governantes Meiji, como é o caso do Quimono infantil de 1930, que representa como as crianças estavam envolvidas pelo tema, figura 06. 

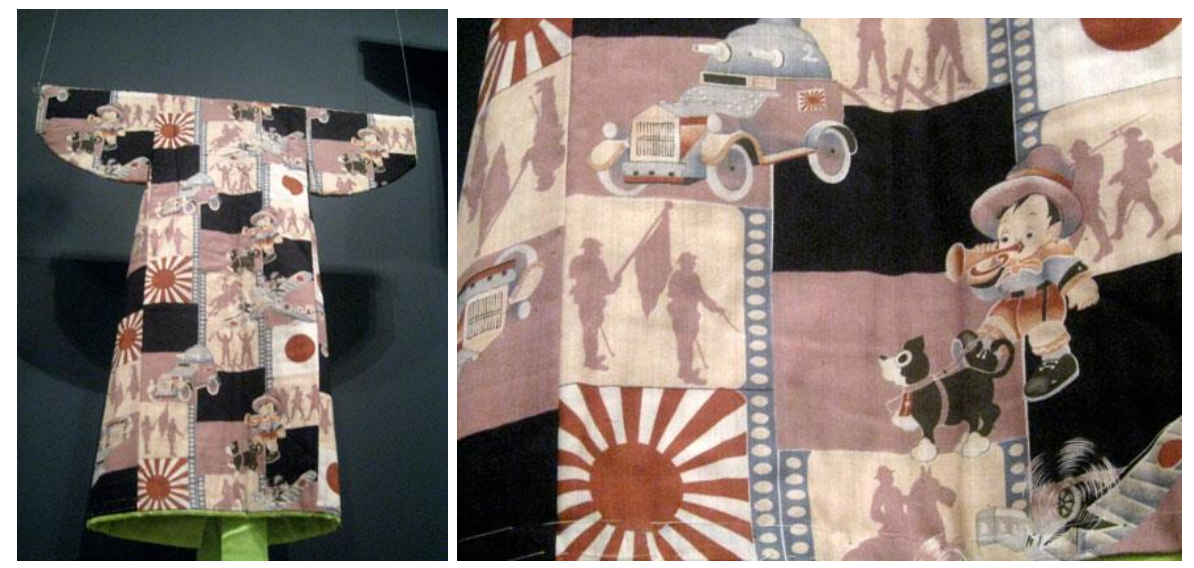

Figura 6 - Quimono infantil com o personagem de mangá Norakuro o cão.

1930

(Fonte: http://www.newyorksocialdiary.com, 2012)

Hitler, depois de 1.933 fechou proibiu todas as organizações infantis, exceto a oficialmente sancionada Juventude Hitlerista, e buscou reforçar a ideologia e a insígnia nazista através de jogos Nazi-temáticos como o SAKAMPF com interesse de preparar rapazes para um papel ativo nas forças armadas, figura 07.

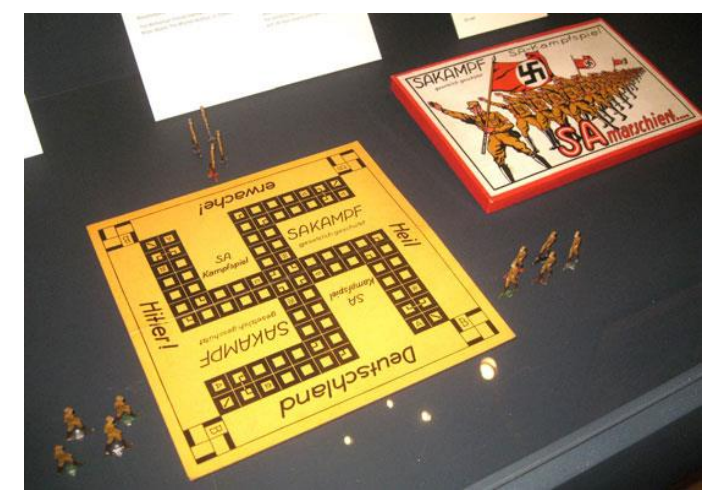

Figura 7 - Jogo de tabuleiro SAKAMPF. 1933

(Fonte: http://www.newyorksocialdiary.com, 2012)

Em países em ambos os eixos da Segunda guerra Mundial surgiram jogos de tabuleiro, quebra-cabeças e brinquedos que a fizeram divertida. Tais produtos familiarizavam as crianças com o tema, influenciando-os positivamente em relação às políticas de combate. $\mathrm{O}$ jogo Gioco delle 3 oche, representava o inimigo como gansos prontos para o abate, figura 08.

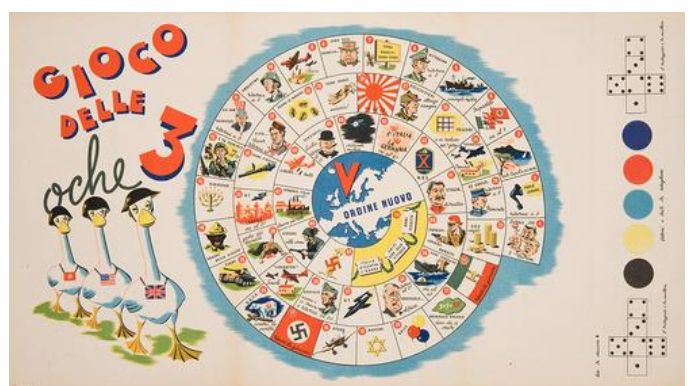

Figura 8 - Gioco delle 3 oche (Jogo das 3 gansos). 1944 
(Fonte: http://centuryofthechild.tumblr.com, 2012)

O impacto da guerra sobre a economia e a produção também surtiu efeito sobre esses produtos, que devido a escassez de materiais, juntamente com a necessidade de construir rapidamente materiais para suprir à demanda por novas escolas do pós-guerra exigiu flexibilidade e desenvoltura. A crença de que as crianças estavam mais à vontade em espaços íntimos, afetou os projetos de escolas do pósguerra, resultando em numerosas escolas menores com pequenos jardins adjacentes às salas de aula resultando em móveis mais leves e portáteis, figura 09.

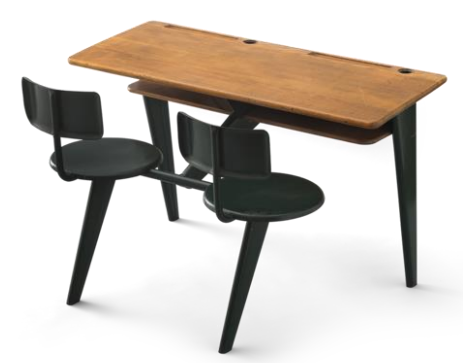

Figura 9 - Jean Prouvé. Mesa da escola. 1946

(Fonte: http://centuryofthechild.tumblr.com, 2012)

A guerra fria e a corrida espacial foram temas recorrentes em produtos dirigidos ao público infantil. Aproximar as descobertas tecnológicas das crianças e desenvolver seu potencial para futuras descobertas aparecia como estratégia fundamental para despontar nessas disputas, como visto nas figuras de 10 e 11 .

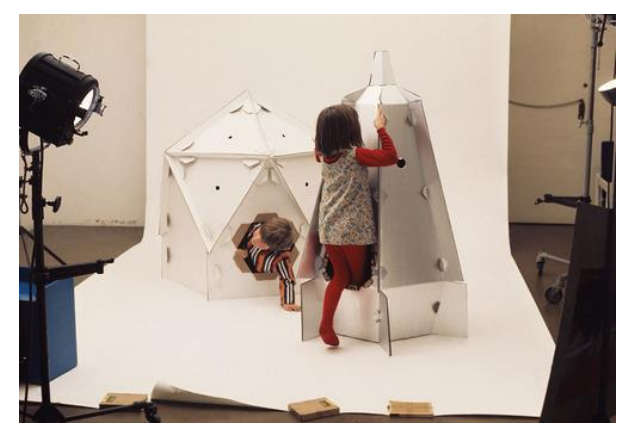

Figura 10 - Estação Espacial e Foguete de papelão. Roger Limbrick.1968.

(Fonte: http://centuryofthechild.tumblr.com, 2012)

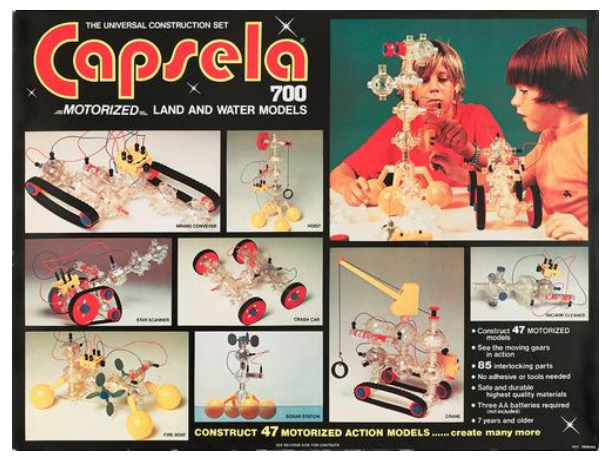


Figura 11 - Capsela 700 jogo da construção. Muitos mecanismos disponibilizados se assemelhavam a instrumentos adequados para a implantação lunar. 1978.

(Fonte: http://centuryofthechild.tumblr.com, 2012)

Nos tempos atuais onde existem esforços para a manutenção da paz, órgãos como a UNICEF também buscam disseminar seus princípios entre as crianças, bem como desenvolver meios de levar assistência a essas nos lugares mais remotos. A School-in-a-Box foi uma caixa de metal contendo materiais necessários para criar uma escola improvisada para oitenta estudantes, incluindo materiais de escrita, o ensino do relógio, fita métrica, tesoura, blocos de plástico para contagem e cadernos, desenvolvida para a prestação de ajuda em situações de desastre e conflito, figura 12.

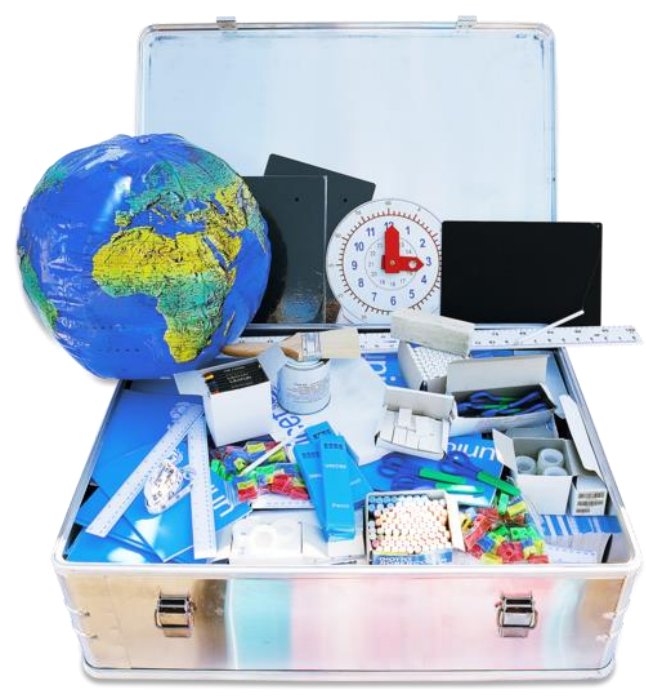

Figura 12 - School-in-a-Box. UNICEF 1994.

(Fonte: http://centuryofthechild.tumblr.com, 2012)

\section{A INFLUÊNCIA DOS MOVIMENTOS ARTÍSTICOS}

Diversos artistas e designers do século XX deram uma atenção especial para esse público, buscando adaptar essa nova cultura aos seus conceitos artísticos.

O armário infantil de Giacomo Balla enfatizava conceitos futuristas como a velocidade da indústria como parte importante da missão futurista para reconstruir a sociedade. Apresentado na primeira exposição Bauhaus de 1923, o conjunto de mobília de Siedhoff-Buscher é considerado por muitos como a primeira verdadeira manifestação de princípios modernistas. Ele reflete sua concepção ambiciosa de design para crianças e sua crença no potencial da área para efetuar a mudança na sociedade em geral, além de a criança individual ou das famílias, figura 13. 


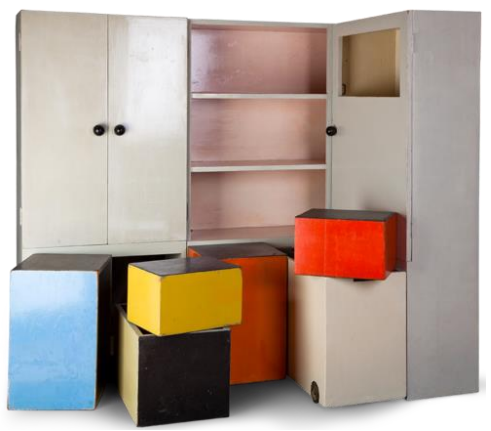

Figura 13 - 1923-1924 Alma Siedhoff-Buscher. Haus am mobília do berçário Horn. (Fonte: http://centuryofthechild.tumblr.com, 2012)

A criação do conceito de Jardim da Infância levou a criação de brinquedos que deveriam auxiliar no desenvolvimento infantil através do método de ensino inspirado pelo movimento de Friedrich Froebel, como o Optical Cor-Mixer, desenvolvido na Bauhaus, produto muito bem aceito na época.

Assim como outros projetos modernistas, o mobiliário infantil de Ray Eames e Charles Eames utilizava a moderna tecnologia da época de madeira curvada aliada ao conceito de inocência e doçura infantil representada pelo coração no encosto. No cabide para chapeis combinaram cores vibrantes cuidadosamente arranjadas para transmitir esses mesmos princípios de delicadeza, figura 14.

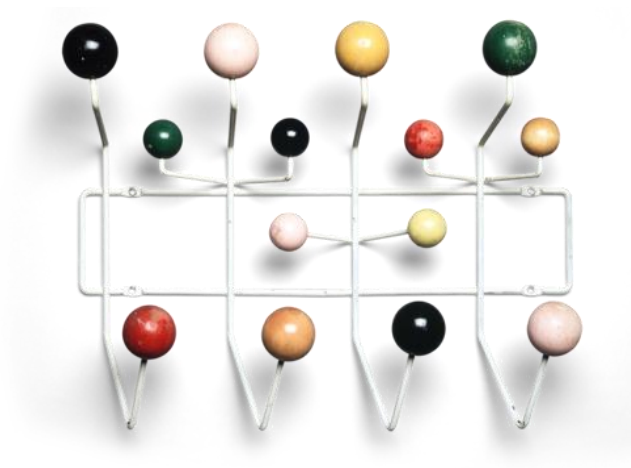

Figura 14 - Ray Eames e Charles Eames. Pendure-It-All chapeleira. 1953.

(Fonte: http://centuryofthechild.tumblr.com, 2012)

\section{PARA A CRIANÇA E PELA CRIANÇA}

Apesar de todos esses esforços para direcionar o desenvolvimento infantil também existiram outros projetos de produtos que buscavam atender as necessidades específicas das crianças de forma desinteressada. No inicio do século XX passou a existir mobília com formas especificas para crianças, que não fossem miniatura da mobília dos adultos, como armários de brinquedos, ou moveis mais fáceis de limpar como os móveis para quarto de crianças Heal's, de 1914, figura 15. 


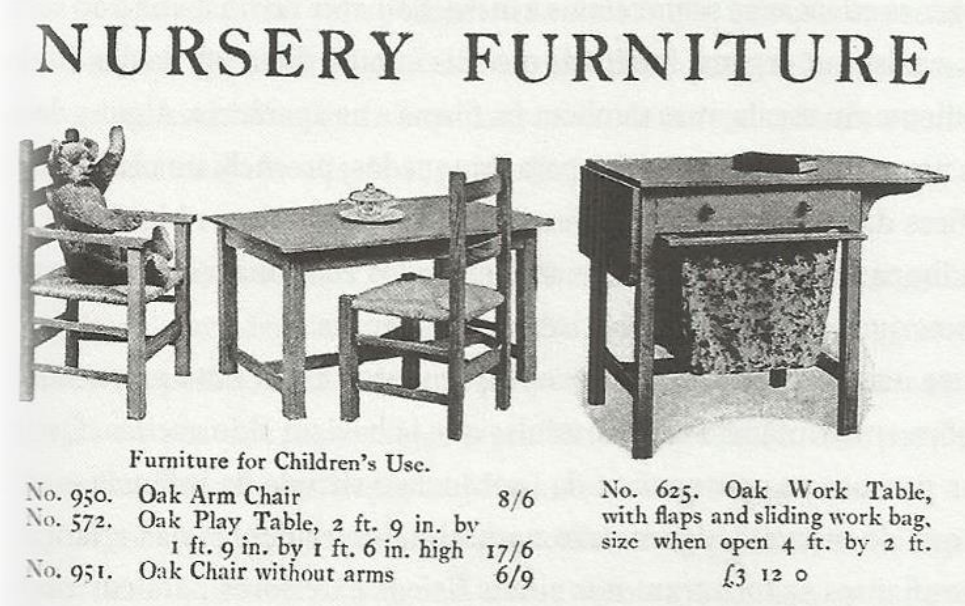

Figura 15 - Heals \& Co, The Nursery Book, s. d. (c.1914).

(Fonte: FORTY, 2007)

A preocupação com o entretenimento infantil no início do século XX pelos reformadores levou com que se reavaliassem os espaços destinados a esse fim. Em 1890 apenas um único parque público existia nos Estados Unidos, a antes de 1900 eles não estavam amplamente disponíveis para as crianças. Começou a aparecer então uma preocupação com o bem-estar físico e moral das crianças, coincidente com o Movimento Playground, nos Estados Unidos. A fim de ensinar lições de boas maneiras, moral e espírito esportivo, foram projetados e instalados playgrounds em diversas cidades para serem refúgios nos quais as crianças podiam escapar temporariamente, através de brincadeiras, as circunstâncias terríveis de seus ambientes urbanos. (DICKASON, 1983). Produtos como o Skippy-Racer também ilustravam uma nova cultura que enfatizava especialmente nas crianças, a liberdade pessoal, mobilidade e escolha do consumidor, figura 16.

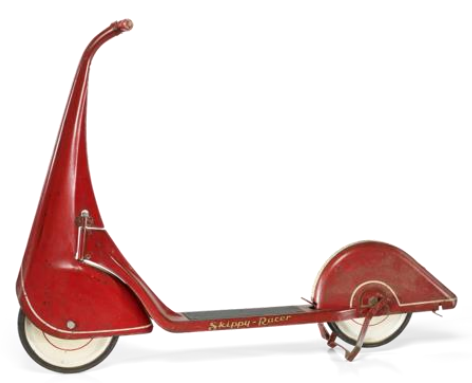

Figura 16 - John Rideout e Harold Van Doren. Skippy-Racer. 1933.

(Fonte: http://www.newyorksocialdiary.com, 2012)

Os objetos criados para atender as supostas necessidades infantis, entretanto, são decorrentes da concepção adulta sobre a infância, o que torna-os as vezes mais um símbolo de identificação da criança na sociedade do que uma ferramenta de construção de sua personalidade. Segundo Brougère (2004) a boneca sob a ótica do adulto passa a significar a criança, enquanto imagem manipulável, embutidas de desejos atribuídos as mesmas. Os adultos colocam as crianças num lugar que ela não sabe, e tentam deduzir como ela pensa e age. (MRECH, 1998) 
Hajime Sorayama é um animal de estimação eletrônico lançado pela Sony em 1999, tem a capacidade de executar determinadas tarefas, tais como lembretes de compromissos e e-mail de notificação, artifícios que nunca antes foram atribuídas ao desenvolvimento infantil, figura 18.

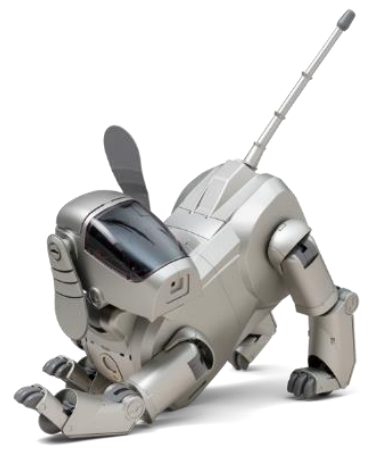

Figura 17 - Hajime Sorayama. Aibo Entretenimento Robot (ERS-110). 1999.

(Fonte: http://centuryofthechild.tumblr.com/, 2012)

\section{NOTAS CONCLUSIVAS}

Através das informações coletadas foi possível avaliar os diferentes interesses que a produção industrial para a criança buscou atender em diferentes contextos histórico-sociais. A importância que passou a se dar a infância trouxe consigo uma análise constante das necessidades desta categoria, e consequentemente uma mudança frequente nas propriedades atribuídas a seu universo. Este histórico de produção nos leva a uma nova interpretação sobre a situação atual do consumo infantil, e uma indagação sobre quais os conceitos que estão sendo transmitidos para as crianças através dos produtos que lhes oferecemos. O design vai ser sempre influenciado pelo contexto histórico, econômico, artístico e cultural, mas o enfoque que se dá aos projetos deve estar inclinado conscientemente para os princípios do profissional e da sociedade que levem às melhores condições de vida e desenvolvimento das crianças.

\section{REFERÊNCIAS}

ÀRIES, P. História social da criança e da família. 2.ed.LCT, 1978.

BENJAMIN, W. Imagens de Pensamento, trad. João Barrento, Lisboa: Assírio \& Alvim, 2004.

BROUGÈRE, G. Brinquedos e companhia. São Paulo: Cortez, 2004.

DICKASON, J. G. 1983. "A origem do Playground:. Papel dos Clubes de Mulheres de Boston, 1885-1890" Ciências de Lazer 6: 83-98

FORTY, A. Objetos de desejo - Design e sociedade desde 1750. São Paulo: Cosaicnaify, 2007.

MERLAU-PONTY, M. Resumo de cursos de Filosofia e Linguagem, Campinas: Papirus, 1990.

MRECH, L. M. Além do sentido e do significado: a concepção psicanalítica da criança e do brincar in 0 brincar e suas teorias. São Paulo: Editora Thomson Learning, 1998.

GONTIJO, S. 80 Anos de Moda no Brasil. Rio de Janeiro: Rocco, 1996. 